\title{
Berberine chloride can ameliorate the spatial memory impairment and increase the expression of interleukin- I beta and inducible nitric oxide synthase in the rat model of Alzheimer's disease
} Feiqi Zhu and Caiyun Qian*

Address: The neurology department of the first affiliated hospital, Sun Yet-Sen University, Guangzhou, Guangdong province, 510080, PR China Email: Feiqi Zhu - zfqzsu2004@yahoo.com.cn; Caiyun Qian* - qiancyzsu@yahoo.com.cn

* Corresponding author

Published: 0 I December 2006

BMC Neuroscience 2006, 7:78 doi:10.1 I86/147|-2202-7-78

This article is available from: http://www.biomedcentral.com/I47/-2202/7/78

(c) 2006 Zhu and Qian; licensee BioMed Central Ltd.

This is an Open Access article distributed under the terms of the Creative Commons Attribution License (http://creativecommons.org/licenses/by/2.0), which permits unrestricted use, distribution, and reproduction in any medium, provided the original work is properly cited.
Received: 26 August 2006

Accepted: 0 I December 2006

\begin{abstract}
Background: Berberine is the major alkaloidal component of Rhizoma coptidis, and has multiple pharmacological effects including inhibiting acetylcholinesterase, reducing cholesterol and glucose, lowering mortality in patients with chronic congestive heart failure and anti-inflammation etc. Thus berberine is a promising drug for diabetes, hyperlipemia, coronary artery disease and ischemic stroke etc. The present study was carried out to investigate the effect of berberine chloride on the spatial memory, inflammation factors interleukin-I beta (IL-Ibeta) and inducible nitric oxide synthase (iNOS) expression in the rat model of Alzheimer's disease (AD) which was established by injecting Abeta (I-40) (5 microgram) into the rats hippocampuses bilaterally.
\end{abstract}

Results: The rats were given berberine chloride $(50 \mathrm{mg} / \mathrm{kg})$ by intragastric administration once daily for 14 days. The spatial memory was assayed by Morris water maze test, IL-Ibeta and iNOS in the hippocampus were assayed by immunohistochemistry and real time polymerase chain reaction (PCR). Intragastric administration of berberine significantly ameliorated the spatial memory impairment and increased the expression of IL-I beta, iNOS in the rat model of AD.

Conclusion: Berberine might be beneficial to $A D$ by intragastric administration though it might exaggerate the inflammation reaction.

\section{Background}

$\mathrm{AD}$ is the most prominent dementia in senile population affecting approximately $5 \%$ of the over 65 -year old populations, but the cause of $\mathrm{AD}$ remains largely unknown. In the pathogenesis of $\mathrm{AD}$, the inflammation mechanism is seemed to play an important role [1]. The senile plaque is the hallmark of $\mathrm{AD}$. The core of the senile plaque is the deposition of $\beta$-amyloid $(A \beta)$ and the activated microglia and astroglia are around the senile plaque. In these glias, numerous inflammation factors including IL- $1 \beta$, interleukin -6(IL-6), tumor necrosis factor- $\alpha$ (TNF- $\alpha$ ) and
iNOS etc, are overexpressed. These inflammation factors have been seemed to be neurotoxic. At the same time, some epidemiological studies demonstrated that longterm use of nonsteroidal anti-inflammatory drugs (NSAIDs) could prominently delay the onset of AD [2-5]. The current drugs for AD treatment including cholinesterase inhibitors (donepezil, rivastigmine and galanthamin) and N-methyl-D-aspartate (NMDA) receptor antagonist (memantine) which were approved by Food and Drug Administration of USA (FDA) are symptomatic treatment, but these drugs usually can not delay the devel- 
opment of AD. Anti-inflammation drugs are expected to delay $\mathrm{AD}$, but most clinical research results of NSAIDs on $\mathrm{AD}$ are negative [6]. Moreover some selective COX-2 inhibitors increased the occurrence of cardiovascular accidents $[7,8]$.

Berberine is an isoquinoline alkaloid with a long history of medicinal usage in China. It exists in Hydrastis canadensis (goldenseal), Cortex phellodendri (Huangbai) and Rhizoma coptidis (Huanglian). These medicinal plants have been widely used as traditional medicines for treating diarrhea and gastrointestinal disorders for a long time in China. Berberine, the major ingredient of these herbs, has multiple pharmacological effects. It is a acetylcholinesterase inhibitor similar to Galanthamine[9], a drug treating $\mathrm{AD}$, and might be a low-molecular-weight neurotrophic drug to neurodegeneration disorder such as AD by potentiating the nerve growth factor (NGF)-induced differentiation in neural cells [10]; berberine is a novel cholesterollowering drug distinctly from statins by stabilizating the low density lipoprotein receptor (LDLR) mRNA to increase LDLR expression and inhibiting lipid synthesis $[11,12]$. Berberine is also able to exert a glucose-lowering effect by insulin independent manner [13], stimulating insulin secretion and effectively sensitizing insulin activity $[14,15]$. So berberine can play an important role on metabolic syndrome. Berberine could improve quality of life and decrease ventricular premature complexes and mortality in patients with chronic congestive heart failure [16]. Berberine has potential in the prevention of atherosclerosis and restenosis $[17,18]$. Berberine can block transient outward potassium current (IA) and delayed rectifier potassium current (IK) in a concentration-dependent manner in acutely isolated CA1 pyramidal neurons of rat hippocampus [19]. A recent study demonstrated that mutations in voltage-gated potassium channel KCNC3 caused adult-onset ataxia [20], and potassium channels are regarded to play a key role in neurodegeneration including $\mathrm{AD}$ [21]. So berberine might be useful for the treatment of neurodegeneration disorders including $\mathrm{AD}$.

Except the above pharmacological effects, extracts obtained from the roots of berberidaceae species have been used in Eastern and Bulgarian folk medicines for the treatment of rheumatic and other chronic inflammatory disorders. Berberine suppressed a delayed type hypersensitivity (DTH) reaction in a chronic inflammatory model of adjuvant arthritis and diminished the antibody response against sensitization red blood cell (SRBC) in vitro [22]. In recent years, it was demonstrated that berberine could inhibit the expression of some inflammation factors. It might inhibit arachidonic acid metabolism in rabbit platelets and endothelial cells [23]. Berberine could decrease cyclooxygenase-2 (COX-2) expression by directly inhibiting the activator protein-1(AP-1) binding and IL$1 \beta$ and TNF- $\alpha$ productions in HepG2 cells and cardiomy-

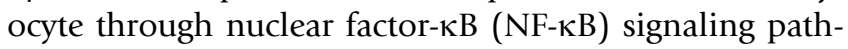
way [24-27]. It could decrease IL-6 production in esophageal cancer cells and inhibit expression of iNOS mRNA in ethanol-induced gastric ulcer mice $[28,29]$.

So berberine might be a very promising drug to treat the cardiac disease, stroke, diabetes and hyperlipoidemia and chronic inflammation diseases. So far, whether berberine might be beneficial to AD by decreasing the inflammation factors expression has not been studied. To test the hypothesis that berberine might inhibit the inflammation factors IL- $1 \beta$ and iNOS expression in the rat model of $A D$, we used the rat model of $\mathrm{AD}$ established by injecting $\mathrm{A} \beta(1-40)(5 \mu \mathrm{g})$ into the bilateral hippocampuses with stereotaxic coordinates and gave the rats berberine chloride $(50 \mathrm{mg} / \mathrm{kg})$ intragastricly for 14 days. It was very surprising that we found berberine chloride could significantly ameliorate the spatial memory impairment and increase these two factors expression.

\section{Results \\ Effects of berberine chloride on the impairment of spatial memory}

Rats were trained in the water maze for 7 days starting at the eighth day after the injection of $A \beta(1-40)(5 \mu \mathrm{g})$. Rats were more efficient at finding the platform on successive trails (Figure 1A). The main effect for each day was significant $(P<0.01)$. The main effect of berberine chloride was also significant $(\mathrm{P}<0.01)$. Two-way repeated measure analysis of variance (two-way RM ANOVA) revealed a significant increase in escape latency to find the platform in the $A \beta(1-40)$-injected group as compared with the normal group $(P<0.01)$ and a significant decrease in escape latency when berberine chloride $(50 \mathrm{mg} / \mathrm{kg}$ ) was intragasticly administrated as compared with the $A \beta(1-40)$ injected group $(\mathrm{P}<0.01)$.

In the retention test (Figure 1B), the number of crossings over a platform position was significantly decreased in the $\mathrm{A} \beta(1-40)$-injected group as compared with that in the normal group $(\mathrm{P}<0.01)$. The crossing number was recovered by treatment with berberine chloride and the recovery was significant $(P<0.01)$. All rats showed normal swimming performance and constant increases in body weight. Locomotor activity did not show difference among groups.

\section{Immunohistochemical evaluation of the effects of berberine chloride on the expression of IL-I $\beta$ and iNOS}

The effects of berberine chloride on the expression of IL$1 \beta$ and iNOS were investigated after the berberine chloride treatment $(50 \mathrm{mg} / \mathrm{kg})$ for 14 days by immunohistochemistry. The injection of $\mathrm{A} \beta(1-40)(5 \mu \mathrm{g})$ in the 

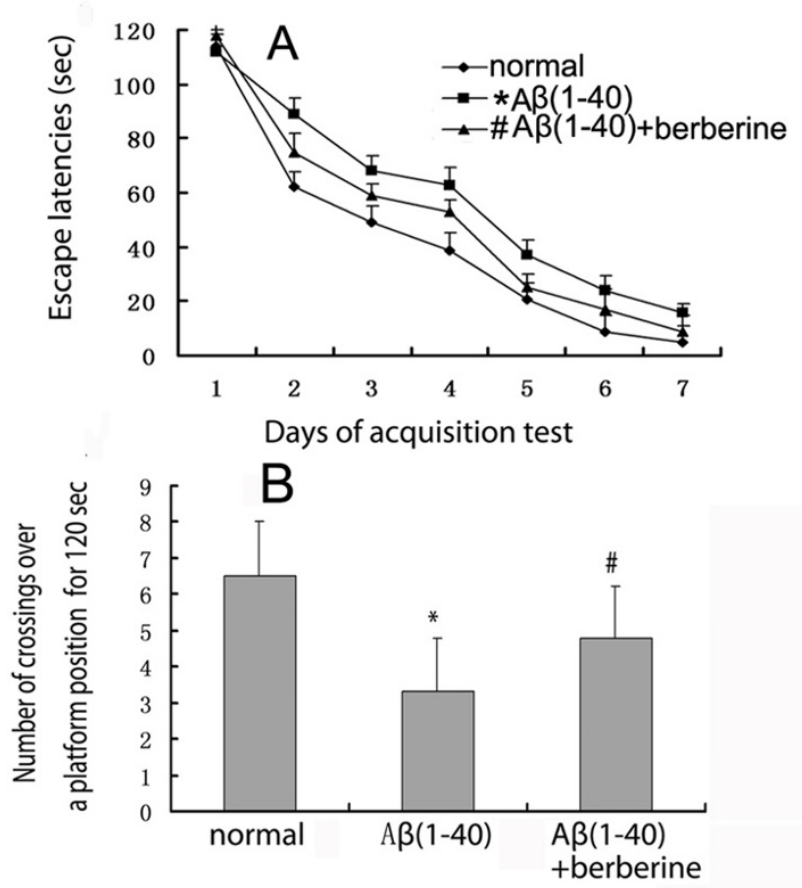

Figure I

Effect of berberine chloride on the impairment of spatial memory induced by $A \beta(I-40)$ injection. $(A)$ Escape latencies per group of four trials tested in a morris water maze over 7 days. (B) The number of crossings over a position where a platform had been was measured for $120 \mathrm{~s}$ at seventh days after the last acquisition test. Values represent the means \pm SD of 6 rats. $* P<0.01$ when compared with the normal group. \# $P<0.01$ when compared with the $A \beta(I-40)$ injection group.

hippocampus highly induced the increase of IL- $1 \beta$ and iNOS immunostainings $(\mathrm{P}<0.01)$, which were more significantly increased in the berberine chloride-treated $\operatorname{rats}(\mathrm{P}<0.01)$ (Figure 2,3). The number of IL-1 $\beta$-positive cells increased from $22.7 \pm 8.3$ (normal group) to $58.8 \pm$ $10.7(\mathrm{~A} \beta(1-40)$ group $)$ and $90.5 \pm 12.2(\mathrm{~A} \beta(1-40)+$ berberine group) (Figure 2D), and the number of iNOS-positive cells also increased from $42.5 \pm 10.2$ (normal group) to $103.0 \pm 13.9$ (A $\beta(1-40)$ group) and $149.5 \pm 11.9$ $(\mathrm{A} \beta(1-40)+$ berberine group) (Figure $3 \mathrm{D})$.

\section{Evaluation of the effects of berberine chloride on the mRNA of IL-I $\beta$ and iNOS by real time PCR}

The effects of berberine chloride on the mRNA of IL-1 $\beta$ and iNOS were investigated after berberine chloride (50 $\mathrm{m} / \mathrm{kg}$ ) treatment for 14 days by real time PCR. Injection of $\mathrm{A} \beta(1-40)(5 \mu \mathrm{g})$ in the hippocampus highly increase the mRNA of IL-1 $\beta$ and iNOS $(P<0.01)$, which were even more significantly increased in the berberine chloridetreated rats $(\mathrm{P}<0.01)$. The relative copies of IL- $1 \beta$ mRNA on internal control $\beta$-actin (arbitrary unit) in the $A \beta(1-$
40) group and $A \beta(1-40)+$ berberine group were increased from $4.3 \pm 1.7$ to $5.8 \pm 2.1$ and $7.3 \pm 1.7$, respectively (Figure $4 \mathrm{~A}$ ), and the relative copies of iNOS mRNA on internal control $\beta$-actin (arbitrary unit) in the above two groups were increased from $20.7 \pm 7.9$ to $33.7 \pm 17.4$ and $67.5 \pm 22.5$, respectively (Figure $4 \mathrm{~B}$ ).

\section{Discussion}

In this study, we observed that berberine chloride $(50 \mathrm{mg} /$ $\mathrm{kg}$ ) could significantly decrease the escape latency and increase the number of crossings over the platform position in the rats model of $\mathrm{AD}$ assayed by Morris water maze test, and could also increase both IL-1 $\beta$ and iNOS expression very significantly assayed by immunohistochemical method. These results are not coincide with the previous studies that berberine could inhibit the expression of iNOS and IL-1 $\beta[26,29]$. The difference between our results and those of previous studies might be due to the different administration mode of berberine and the effect that berberine can increase non-specific immunity. Berberine was intraperitoneally administrated or used in cells culture model in the reported studies in contrast to the intragastric administration in the present experiment. The uptake rate of berberine by intragastric administration is very low [30]. So the concentration of berberine in blood or cell culture medium in the reported studies is higher than the level in the present investigation. The different level of berberine may cause different effects on the immunity and inflammation factors' expression.

Berberine has been used by oral administration as an unprescribed drug in China, and the safety and efficacy of berberine by this administration mode have been generally accepted. Moreover, berberine $(50 \mathrm{mg} / \mathrm{kg}-100 \mathrm{mg} /$ $\mathrm{kg}$ ) by intragastric administration can significantly exert cholesterol-lowering effect on rats [11]. So in this study, we chosed the dose $50 \mathrm{mg} / \mathrm{kg}$ to study berberine's effect on the expression of IL-1 $\beta$ and iNOS because this dose and administration mode are more close to the clinical practice than veno-injection or intraperitoneal administration. We presume that the increase of inflammation factors IL- $1 \beta$ and iNOS might be related to the rising of microglia activation. In another two previous studies, berberine was demonstrated to be able to activate macrophages and increase the phagcytosing function of peritoneal macrophages (PM $\Phi)$ and the production of IL1 by PM $\Phi$ in mice $[31,32]$. It is indicated that berberine is a potent macrophage activator and can increase non-specific immunity. Moreover it was demonstrated that berberine could decrease the expression of PPAR $\gamma_{2}$ mRNA and protein which was a negative regulator of inflammation[33,34]. Microglia and PMФ are originated from the peripheric mononuclear macrophage. So berberine might be able to activate the microglia to phagocytize the exogenous $A \beta(1-40)$ which was injected into hippocampus. In 

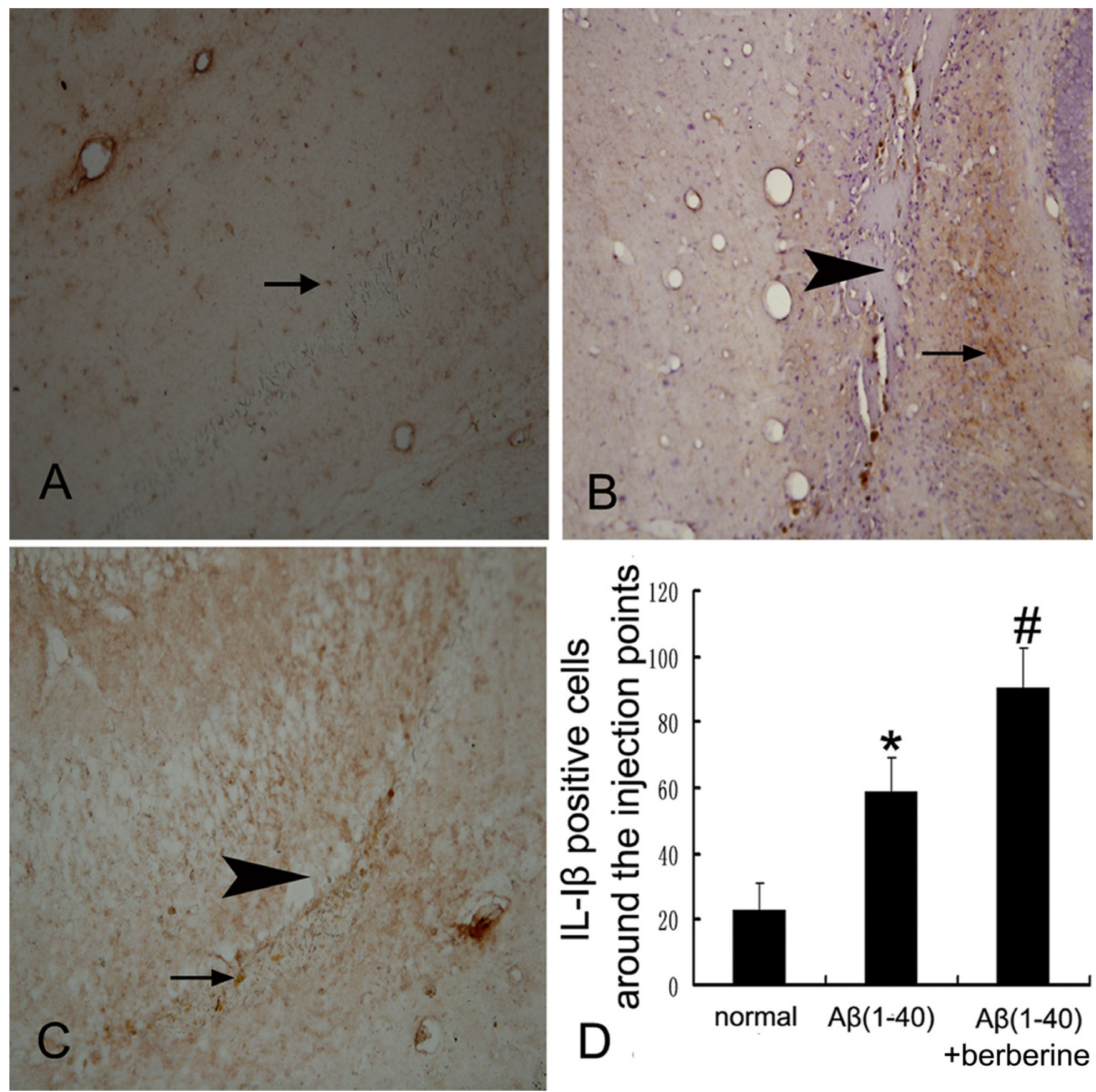

\section{Figure 2}

Immunohistochemistrical evaluation of the effect of berberine chloride on the expression of IL-I $\beta$. (A) the expression of IL-I $\beta$ (arrow) in the normal rat hippocampus.(B) the expression of IL-I $\beta$ (arrow) around the injection point (arrowhead) in the $A \beta(I-40)$ group. $(C)$ the expression of IL-I $\beta$ (arrow) around the injection point (arrowhead) in the $A \beta(I-$ $40)+$ berberine group.(D) the table represents the number of IL-I $\beta$ positive cells around the injection point in $400 \times$ fields. Values represent the means $\pm S D$ of 6 rats. $* P<0.01$ when compared with the normal group. \# $P<0.01$ when compared with the $A \beta(I-40)$ group. $(A, B, C: 200 x)$ 

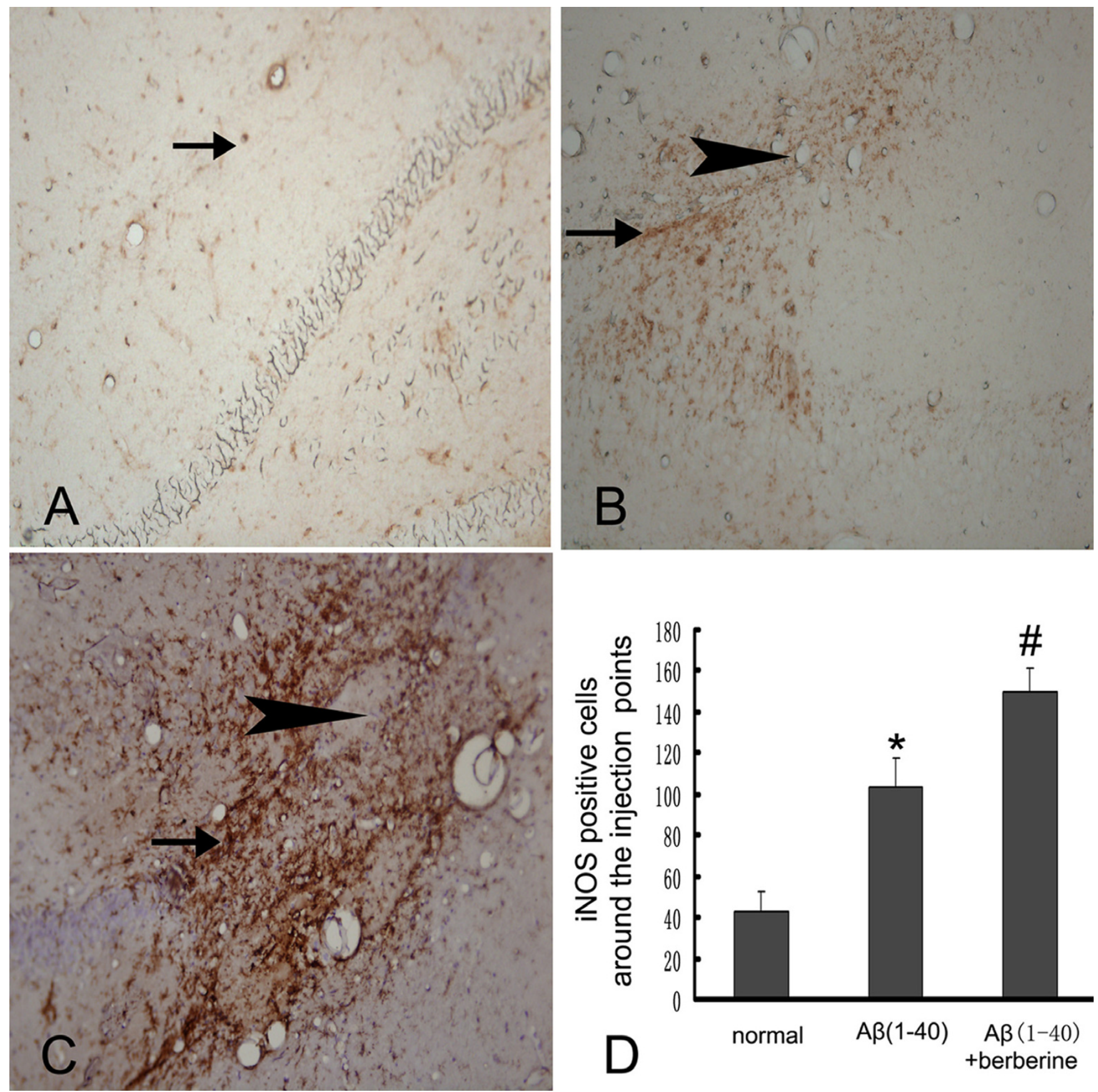

\section{Figure 3}

Immunohistochemistrical evaluation of the effect of berberine chloride on the expression of iNOS. (A) the expression of iNOS(arrow) in the normal rat hippocampus. (B) the expression of iNOS(arrow) around the injection point (arrowhead) in the $A \beta(I-40)$ group. (C) the expression iNOS (arrow) of around the injection point (arrowhead) in the $A \beta(I-$ 40)+berberine group.(D) the table represents the number of iNOS positive cells around the injection point in $400 \times$ fields. Values represent the means $\pm S D$ of 6 rats. $* P<0.01$ when compared with the normal group. \# $P<0.01$ when compared with the $A \beta(I-40)$ group. $(A, B, C: 200 x)$ 

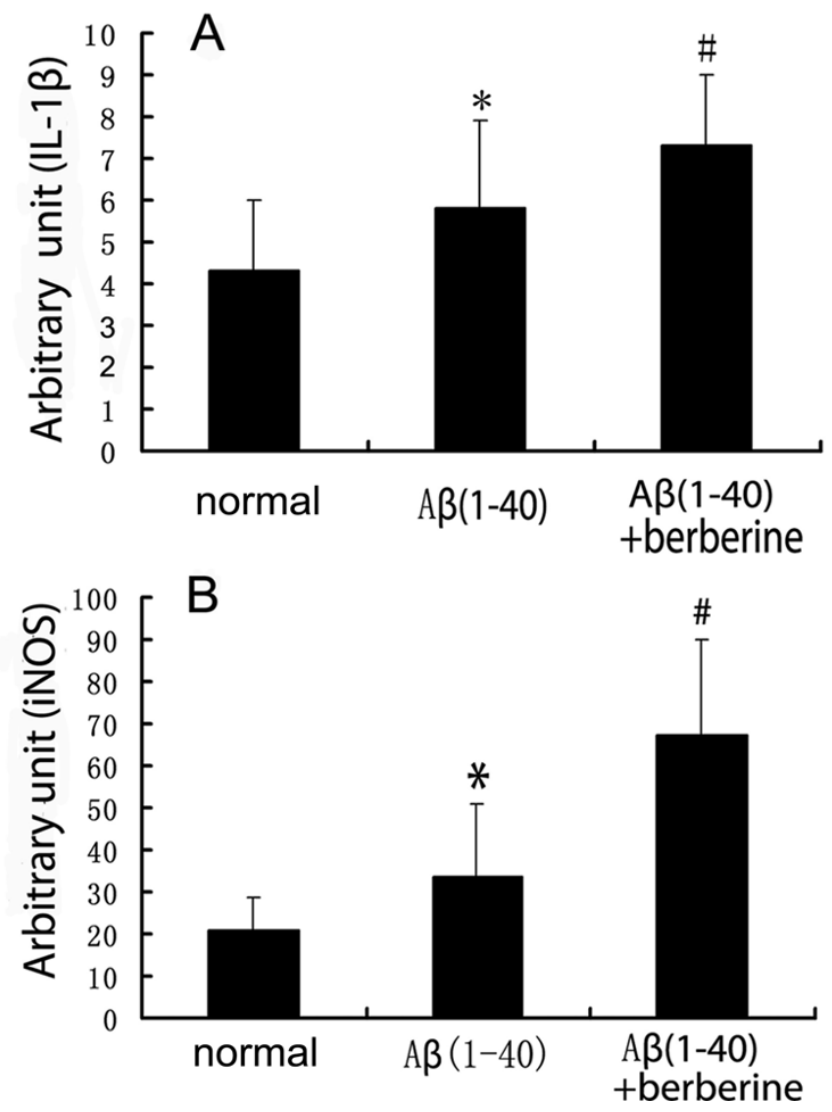

Figure 4

Evaluation of the effects of berberine chloride on the mRNA of IL-I $\beta$ and iNOS by Real time PCR. (A)Real time PCR results of berberine chloride on the IL-I $\beta$ mRNA indicate that IL-I $\beta$ mRNA level was increased in the $A \beta(I-$ $40)$ group and $A \beta(1-40)+$ berberine group. The result represents at least three independent experiments, and $\beta$-actin was used as an internal control.(B) Real time PCR results of berberine chloride on the iNOS mRNA indicates that iNOS mRNA level was increased in the $A \beta(I-40)$ group and $A \beta(I-$ $40)+$ berberine group. The result represents at least three independent experiments, and $\beta$-actin was used as an internal control. Values represent the means $\pm S D$ of 6 rats. *P $<0.01$ when compared with the normal group. \# $\mathrm{P}<0.01$ when compared with the $A \beta(I-40)$ injection group.

another our study, we had also demonstrated that berberine was able to increase the microglia activation and significantly decrease the expression $\mathrm{PPAR}_{\gamma}$ after the injection of $A \beta(1-40)$ into the hippocampus (data not shown). So in this study, berberine should be able to increase the inflammation factors expression including IL-1 $\beta$ and iNOS by increasing microglia activation.

It seems that berberine might not be beneficial to AD because it can increase the inflammation factors' expres- sion and microglia activation. But inflammation factors might also be beneficial to central nervous system (CNS). It was reported that IL- $1 \beta$ might be crucial to the repair of the CNS presumably through the induction of astrocyte and microglia-macrophage-derived insulin-like growth factor-1(IGF-1), and IL-1 $\beta^{--/}$mice failed to remyelinate properly which was correlated to the lack of IGF-1 production by microglia-macrophages and astrocytes and to a profound delay of precursors differentiating into mature oligodendrocytes [35]. So berberine might ameliorate the pathologies of AD through increasing the expression of IL$1 \beta$. At the same time, a very recent study demonstrated that genetic removal of iNOS in mice expressing mutated amyloid precursor protein resulted in pathological hyperphosphorylation of mouse tau, its redistribution to the somatodendritic compartment in cortical and hippocampal neurons, and aggregate formation. Lack of iNOS in the amyloid precursor protein Swedish mutant mouse would increase the insoluble $\mathrm{A} \beta$ levels, neuronal degeneration, caspase- 3 activation and tau cleavage. This phenomenon suggested that nitric oxide (NO) acted as a junction point between $\mathrm{A} \beta$, caspase activation, and tau aggregation, and iNOS deletion could promote multiple pathologies in a mouse model of AD [36]. So berberine might be able to ameliorate the multiple pathologies of $\mathrm{AD}$ by increasing iNOS expression. Moreover, berberine might be beneficial to the senile plaque clearance by increasing microglia activation. A recent study demonstrated that bone marrowderived microglia played a critical role in restricting senile plaque formation in $\mathrm{AD}$, and therapeutic strategies aiming to improve bone marrow-derived microglia recruitment could potentially lead to a new powerful tool for the elimination of toxic senile plaques [37]. Another recent study also demonstrated that suppressing microglia activation and reducing inflammation factors expression by minocycline could enhance senile plaque formation [38]. Moreover $\mathrm{AD}$ might be associated with the aging of microglia for postnatal microglia, non-adult microglia has the ability to phagocytose $A \beta$ fibrils[39]. The above studies indicated that anti-inflammation drugs might not be beneficial to $\mathrm{AD}$, which is consistent with the vague effect of this kind of drugs including NSAIDs on AD. So berberine might be beneficial to $\mathrm{AD}$ by enhancing the bone barrow derived mononuclear macrophage to cross the bloodbrain barrier (BBB) and to be activated microglia which has the ability to phagocytose $A \beta$ fibrils, clear the senile plaque and produce the more inflammation factors.

\section{Conclusion}

Berberine might be beneficial to AD by ameliorating spatial memory impairment, improving inflammation factors expression, activating microglia and the senile plaque clearance. But further investigation is needed in AD transgenic models and clinical research to demonstrate the efficacy of berberine to AD. 


\section{Methods \\ Animals and drug treatments}

Adult male Sprague-Dawley rats ( $\mathrm{n}=18)(220-250 \mathrm{~g}$, experimental animal center of Sun Yet-Sen University) were housed 6 per cage with free access to food and water, and were kept in a constant environment $\left(22 \pm 2^{\circ} \mathrm{C}, 50 \pm\right.$ $5 \%$ humidity, 12 -h light/dark cycle). The rats were randomly divided into three groups, including the normal group, the $A \beta(1-40)$ group and $A \beta(1-40)+$ berberine group. $A \beta(1-40)$ (Sigma, St. Louis, MO.USA) was dissolved in sterile distilled water at a concentration of $5 \mu \mathrm{g} /$ $\mu \mathrm{L}$, and incubated at $37^{\circ} \mathrm{C}$ for 7 days to obtain the aggregated form. Under anesthetization, peptides $(1 \mu \mathrm{L}=5 \mu \mathrm{g})$ were injected into the bilateral hippocampuses, with stereotaxic coordinates from the bregma being, in mm, A -3, L/R-2.0, and V 3.5. After analepsia, berberine chloride (50 $\mathrm{mg} / \mathrm{kg}$ ) (Sigma, St. Louis, MO. USA) was administered intragastricly once daily for 14 days. All experimental animals were overseen and approved by the Animal Care and Use Committee of Sun Yet-Sen University before and during experiments.

\section{Morris water maze test}

White-colored water was poured into a circular pool (diameter, $120 \mathrm{~cm}$; height, $28 \mathrm{~cm}$ ), and a white platform (diameter, $8.3 \mathrm{~cm}$ ) was placed $1.5 \mathrm{~cm}$ below the water level in the middle of a fixed quadrant. The water temperature was adjusted to $25 \pm 1^{\circ} \mathrm{C}$. Memory-acquisition trials (training) were performed four times daily for 7 days to reach a steady state of escape latency. At $1 \mathrm{~h}$ after intragastric administration of berberine chloride, the rats were allowed to swim freely for $120 \mathrm{~s}$ and were left for an additional $30 \mathrm{~s}$ on the platform. The intertribal interval during four trials was $75 \mathrm{~min}$. Start positions set at each limit between quadrants, were randomly selected for each animal. Rats failing to find the platform were placed on the platform manually. Memory-retention tests were performed at the seventh day after the last training session. The platform was removed, and each rat was allowed a free $120 \mathrm{~s}$ swim. The number of crossings over a point where the platform had been was counted by replay using a video recorder. Data are presented as mean \pm SD.

\section{Immunohistochemistry}

Animals were perfused through the heart under deep anaesthesia (chloral hydrate $0.35 \mathrm{~mL} / 100 \mathrm{~g}$ ) with $100 \mathrm{~mL}$ of phosphate buffer saline (PBS) containing $10 \mathrm{U} / \mathrm{mL}$ heparin followed by $150-200 \mathrm{~mL}$ of $4 \%$ paraformaldehyde in PBS, PH 7.4. Brains were removed and then immersed in PBS containing sucrose, PH 7.4, first in 20\% sucrose for $24 \mathrm{~h}$ and then in 30\% sucrose until sunk (2-5 days). $8 \mu \mathrm{m}$ sections were cut on a cryostat and mounted in polylysine -coated slices. The number of IL-1 $\beta$ and iNOS positive cells around the point of injection were analyzed immunohistochemically using an antibody against IL-1 $\beta$ (sc-7784, dilution 1:50, Santa Cruz Biotechnology Inc., USA) and anibody against iNOS (SC-651, dilution 1:50, Santa Cruz Biotechnology, Inc.USA.). For the visualization under light microscope, incubation with biotinylated rabbit/mouse anti-rat IgG (Dako Cytomation Inc., USA) and the immunoreaction was visualized using diaminobenzidine. Counting of IL- $1 \beta$ and iNOS -expressing cells was done by an observer blind to the treatment status of the rats based on the visibility of a cell soma in 8 $\mu \mathrm{m}$-thick coronal sections in $400 \times$ fields by Olysia Bioreport software (Olympus company, Japan). Four slides around the injection point were evaluated per animal. Data are presented as mean \pm SD.

\section{Real time PCR}

Expressions of genes were further confirmed by real time PCR. Primers were designed and synthesized by Takara biotechnology Co., Ltd (Dalian, China). Total RNA was isolated from hippocampus tissues using RNAiso reagent (Takara biotechnology Co., Ltd, Dalian, China). Firststrand cDNA was synthesized from $0.5 \mu \mathrm{g}$ of total cellular RNA with randoms 6 mers with the ExScript ${ }^{\mathrm{TM}}$ RT Reagents Kit (Takara biotechnology Co., Ltd, Dalian, China). After incubation for $15 \mathrm{mins}$ at $42^{\circ} \mathrm{C}$, the RT mixture was incubated at $95^{\circ} \mathrm{C}$ for $2 \mathrm{~min}$ to inactivate the reverse transcriptase. Real time PCR cycles were carried out for amplification of IL- $1 \beta$, iNOS and $\beta$-actin cDNA using a thermal cycler (MJ Research company, DFC-3200, USA). The primers sequences for IL- $1 \beta$ were 5 '- GCT GTG GCA GCT ACC TAT GTC TTG -3' (sense) and 5'- AGG TCG TCA TCA TCC CAC GAG -3' (antisense). The primer sequences for iNOS were 5'- CTC ACT GTG GCT GTG GTC ACC TA -3' (sense) and 5'- GGG TCT TCG GGC TTC AGG TTA -3' (antisense). The primer sequences for $\beta$-actin were 5 '- TGA CAG G TG CAG AAG GAG A -3'(sense) and 5'- TAG AGC CAC CAA TCC ACA CA-3'(antisense). Real time PCR was then carried out using $2 \mu \mathrm{L}$ cDNA in a final reaction volume $20 \mu \mathrm{L}$ using SYBR Premix Ex Taq ${ }^{\mathrm{TM}}$ (Takara biotechnology Co., Ltd, Dalian, China). The PCR cycling program was set for 1 cycle of pre-denaturation at $95^{\circ} \mathrm{C}$ for $10 \mathrm{~s}$, and then 39 cycles at $95^{\circ} \mathrm{C}$ for $5 \mathrm{~s}, 60^{\circ} \mathrm{C}$ for $20 \mathrm{~s}, 81^{\circ} \mathrm{C}$ plate reading for $3 \mathrm{~s}$, melting curve from $55^{\circ} \mathrm{C}$ to $95^{\circ} \mathrm{C}$ read every $0.2^{\circ} \mathrm{C}$ hold for $1 \mathrm{~s}$ between reads. The relative copies of IL- $1 \beta$ mRNA and iNOS mRNA on the internal control $\beta$-actin are arbitrary units.

\section{Statistical analysis}

All of the data were expressed as mean \pm SD and the analysis was carried out using the one way analysis of variance(ANOVA) or two-way RM ANOVA. Values of $\mathrm{P}<0.05$ were considered statistically significant.

\section{Abbreviations}

AD: Alzheimer's disease 
PCR: polymerase chain reaction

IL-1 $\beta$ : Interleukin-1 $\beta$

iNOS : Inducible nitric oxide synthase

IGF-1:insulin-like growth factor-1

NO: nitric oxide

PBS: phosphate buffer saline

\section{Authors' contributions}

FZ and CQ participated in the design of the study. FZ carried out the spatial memory test, immunohistochemistry, real time PCR, performed the statistical analysis and wrote the manuscript. All authors read and approved the final manuscript.

\section{Acknowledgements}

We wish to thank Dr. Renwang Jiang for assistance in manuscript writing. This study was supported by the National Natural Science Foundation of China (39370264).

\section{References}

I. Akiyama H, Barger S, Barnum S, Bradt B, Bauer J, Cole GM, Cooper NR, Eikelenboom P, Emmerling M, Fiebich BL, Finch CE, Frautschy S, Griffin WS, Hampel H, Hull M, Landreth G, Lue L, Mrak R, Mackenzie IR, McGeer PL, O'Banion MK, Pachter J, Pasinetti G, Plata-Salaman C, Rogers J, Rydel R, Shen Y, Streit W, Strohmeyer R, Tooyoma I, Van Muiswinkel FL, Veerhuis R, Walker D, Webster S, Wegrzyniak B, Wenk G, Wyss-Coray T: Inflammation and Alzheimer's disease. Neurobiol Aging 2000, 21 (3):383-42I.

2. Etminan M, Gill S, Samii A: Effect of non-steroidal anti-inflammatory drugs on risk of Alzheimer's disease: systematic review and meta-analysis of observational studies. BMJ 2003, 327(7407): 128.

3. Yip AG, Green RC, Huyck M, Cupples LA, Farrer LA: Nonsteroidal anti-inflammatory drug use and Alzheimer's disease risk: the MIRAGE Study. BMC Geriatr 2005, 5:2.

4. Anthony JC, Breitner JC, Zandi PP, Meyer MR, Jurasova I, Norton MC, Stone SV: Reduced prevalence of AD in users of NSAIDs and $\mathrm{H} 2$ receptor antagonists: the Cache County study. Neurology 2000, 54(II):2066-207I.

5. Stewart WF, Kawas C, Corrada M, Metter EJ: Risk of Alzheimer's disease and duration of NSAID use. Neurology 1997, 48(3):626-632.

6. Aisen PS, Schafer KA, Grundman M, Pfeiffer E, Sano M, Davis KL, Farlow MR, Jin S, Thomas RG, Thal LJ, Alzheimer's Disease Cooperative Study: Effects of rofecoxib or naproxen vs placebo on Alzheimer disease progression: a randomized controlled trial. JAMA 2003, 289(2I):2819-2826.

7. Justice $E$, Carruthers DM: Cardiovascular risk and COX-2 inhibition in rheumatological practice. J Hum Hypertens 2005, 19(I): I-5.

8. Mukherjee D, Nissen SE, Topol EJ: Risk of cardiovascular events associated with selective COX-2 inhibitors. JAMA 200I, 286(8):954-959.

9. Ingkaninan K, Phengpa P, Yuenyongsawad S, Khorana N: Acetylcholinesterase inhibitors from Stephania venosa tuber. J Pharm Pharmacol 2006, 58(5):695-700.

10. Shigeta K, Ootaki K, Tatemoto H, Nakanishi T, Inada A, Muto N: Potentiation of nerve growth factor-induced neurite outgrowth in PCI 2 cells by a Coptidis Rhizoma extract and protoberberine alkaloids. Biosci Biotechnol Biochem 2002, 66(II):249I-2494.

II. Kong W, Wei J, Abidi P, Lin M, Inaba S, Li C, Wang Y, Wang Z, Si S, Pan H, Wang S, Wu J, Wang Y, Li Z, Liu J, Jiang JD: Berberine is a novel cholesterol-lowering drug working through a unique mechanism distinct from statins. Nat Med 2004, I0( I 2): I344-135I.

12. Brusq JM, Ancellin N, Grondin P, Guillard R, Martin S, Saintillan Y, Issandou M: Inhibition of lipid synthesis through activation of AMP kinase: an additional mechanism for the hypolipidemic effects of berberine. J Lipid Res 2006, 47(6): | 28I- 1288.

13. Yin J, Hu R, Chen M, Tang J, Li F, Yang Y, Chen J: Effects of berberine on glucose metabolism in vitro. Metabolism 2002, 5 I(II): 1439-1443.

14. Leng SH, Lu FE, Xu LJ: Therapeutic effects of berberine in impaired glucose tolerance rats and its influence on insulin secretion. Acta Pharmacol Sin 2004, 25(4):496-502.

15. Ko BS, Choi SB, Park SK, Jang JS, Kim YE, Park S: Insulin sensitizing and insulinotropic action of berberine from Cortidis rhizoma. Biol Pharm Bull 2005, 28(8): I43I-I 437.

16. Zeng $X H$, Zeng $X J, L i ~ Y Y$ : Efficacy and safety of berberine for congestive heart failure secondary to ischemic or idiopathic dilated cardiomyopathy. Am J Cardiol 2003, 92(2): 173-176.

17. Lee S, Lim HJ, Park HY, Lee KS, Park JH, Jang Y: Berberine inhibits rat vascular smooth muscle cell proliferation and migration in vitro and improves neointima formation after balloon injury in vivo. Berberine improves neointima formation in a rat model. Atherosclerosis 2006, I86(I):29-37.

18. Liang KW, Ting CT, Yin SC, Chen YT, Lin SJ, Liao JK, Hsu SL: Berberine suppresses MEK/ERK-dependent Egr-I signaling pathway and inhibits vascular smooth muscle cell regrowth after in vitro mechanical injury. Biochem Pharmacol 2006, $7 I(6): 806-8 I 7$.

19. Wang F, Zhao G, Cheng L, Zhou HY, Fu LY, Yao WX: Effects of berberine on potassium currents in acutely isolated CAI pyramidal neurons of rat hippocampus. Brain Res 2004, 999(1):91-97.

20. Waters MF, Minassian NA, Stevanin G, Figueroa KP, Bannister JP Nolte D, Mock AF, Evidente VG, Fee DB, Muller U, Durr A, Brice A, Papazian DM, Pulst SM: Mutations in voltage-gated potassium channel KCNC3 cause degenerative and developmental central nervous system phenotypes. Nat Genet 2006, 38(4):447-45।.

2I. Nelson R: Potassium channels have a key role in neurodegeneration. Lancet Neurol 2006, 5(4):298-299.

22. Ivanovska N, Philipov S: Study on the anti-inflammatory action of Berberis vulgaris root extract, alkaloid fractions and pure alkaloids. Int J Immunopharmacol 1996, I8(10):553-56I.

23. Huang CG, Chu ZL, Wei SJ, Jiang H, jiao BH: Effect of berberine on arachidonic acid metabolism in rabbit platelets and endothelial cells. Thromb Res 2002, 106(4-5):223-227.

24. Kuo CL, Chi CW, Liu TY: The anti-inflammatory potential of berberine in vitro and in vivo. Cancer Lett 2004, 203(2): I 27-I37.

25. Fukuda K, Hibiya Y, Mutoh M, Koshiji M, Akao S, Fujiwara : Inhibition by berberine of cyclooxygenase-2 transcriptional activity in human colon cancer cells. J Ethnopharmacol 1999, 66(2):227-233.

26. Hsiang CY, Wu SL, Cheng SE, Ho TY: Acetaldehyde-induced interleukin-Ibeta and tumor necrosis factor-alpha production is inhibited by berberine through nuclear factor-kappaB signaling pathway in HepG2 cells. J Biomed Sci 2005, I 2(5):79|-80|.

27. Yang J, Wang HD, Lu DX, Wang YP, Qi RB, Li J, Li F, Li CJ: Effects of neutral sulfate berberine on LPS-induced cardiomyocyte TNF-alpha secretion, abnormal calcium cycling, and cardiac dysfunction in rats. Acta Pharmacol Sin 2006, 27(2): I73-178.

28. lizuka N, Miyamoto K, Hazama S, Yoshino S, Yoshimura K, Okita K, Fukumoto T, Yamamoto S, Tangoku A, Oka M: Anticachectic effects of Coptidis rhizoma, an anti-inflammatory herb, on esophageal cancer cells that produce interleukin 6. Cancer Lett 2000, I 58(I):35-4I.

29. Pan LR, Tang Q, Fu Q, Hu BR, Xiang JZ, Qian JQ: Roles of nitric oxide in protective effect of berberine in ethanol-induced gastric ulcer mice. Acta Pharmacol Sin 2005, 26(I I):I334-1338.

30. Shen Mei-pin, Sun Qi, Wang Hong: Studies on the intravenous pharmacokinetics and oral absorbtion of berberine $H C L$ in beagle dogs. Chinese Pharmocological Bulletin 1993, 9(I):64-67.

31. Kumazawa Y, Itagaki A, Fukumoto M, Fujisawa $H$, Nishimura C, Nomoto K: Activation of peritoneal macrophages by berber- 
ine-type alkaloids in terms of induction of cytostatic activity. Int J Immunopharmacol 1984, 6(6):587-592.

32. Geng Dong-Sheng, Liu Fa, Liu Xue-Bin, Yang Yong-xin: Effects of berberine sulphate on immune system. Chinese Pharmacological Bulletin 1996, I 2(6):536-539.

33. Huang C, Zhang Y, Gong Z, Sheng X, Li Z, Zhang W, Qin Y: Berberine inhibits 3T3-LI adipocyte differentiation through the PPARgamma pathway. Biochem Biophys Res Commun 2006, 348(2):57I-578.

34. Zhou Li-Bin, Chen Ming-dao, Wang Xiao, Song, Huai-dong, YANG Ying: Effect of berberine on the differentiation of adipocyte. Natl Med J China 2003, 83(4):338-340.

35. Mason JL, Suzuki K, Chaplin DD, Matsushima GK: InterleukinIbeta promotes repair of the CNS. J Neurosci 200I, 2I(1 8):7046-7052.

36. Colton CA, Vitek MP, Wink DA, Xu Q, Cantillana V, Previti ML, Van Nostrand WE, Weinberg JB, Dawson H: NO synthase 2 (NOS2) deletion promotes multiple pathologies in a mouse model of Alzheimer's disease. Proc Natl Acad Sci USA 2006, I03(34): | 2867- 12872.

37. Simard AR, Soulet D, Gowing G, Julien JP, Rivest S: Bone marrowderived microglia play a critical role in restricting senile plaque formation in Alzheimer's disease. Neuron 2006, 49(4):489-502.

38. Seabrook TJ, Jiang L, Maier M, Lemere CA: Minocycline affects microglia activation, Abeta deposition, and behavior in APPtg mice. Glia 2006, 53(7):776-782.

39. Floden AM, Combs CK: Beta-amyloid stimulates murine postnatal and adult microglia cultures in a unique manner. J Neurosci 2006, 26(I7):4644-4648.

Publish with Bio Med Central and every scientist can read your work free of charge

"BioMed Central will be the most significant development for disseminating the results of biomedical research in our lifetime. "

Sir Paul Nurse, Cancer Research UK

Your research papers will be:

- available free of charge to the entire biomedical community

- peer reviewed and published immediately upon acceptance

- cited in PubMed and archived on PubMed Central

- yours - you keep the copyright 